\title{
Cezary Kraśkiewicz
}

Mgr inż.

Politechnika Warszawska, Wydział

Inżynierii Lądowej, Instytut Dróg i Mostów

c.kraskiewicz@il.pw.edu.pl

\section{Wojciech Oleksiewicz}

Dr inż.

Politechnika Warszawska, Wydział

Inżynierii Lądowej, Instytut Dróg i Mostów

w.oleksiewicz@il.pw.edu.pl

\section{Kacper Wasilewski}

Mgr inż.

Politechnika Warszawska, Wydział

Inżynierii Lądowej, Instytut Inżynierii Budowlanej

k.wasilewski@il.pw.edu.pl

DOI: 10.35117/A_ENG_19_05_02

\section{Selected laboratory tests on under sleeper pads (USP) used in the railway track system}

Abstract: In the present paper results of the tests for fatigue strength and resistance to severe environ-mental conditions performed on several prototypical under sleeper pads (USP) are presented. The work includes results of the static and dynamic tests carried out on samples of three materials, which were used to produce the USP. The fatigue tests were performed up to 500 thousand load cycles and they aimed at determining which of the analysed USP have favourable properties, taking into account their potential application as the elements used for reduction of stresses in the ballast - especially in the ballast layer directly under the sleeper and reduction of the material and acoustic vibration emitted to the railway track's surrounding (vibration and noise). In the climatic tests that were aimed at determining the influence of severe environmental conditions on the properties of USP, the samples were attached to concrete blocks and immersed in water for $24 \mathrm{~h}$ and then placed in a climatic chamber, where they were subjected to freeze-thaw cycles. The results show that both the fatigue and climatic tests have influence on the damping-related parameters of the USP, what affects the effectiveness of the vibration isolation.

Keywords: Under sleeper pads (USP); Material tests; Stiffness; Durability; Resistance to severe environmental conditions

\section{Introduction}

The under sleeper pads $[1,3,5,6,7,11]$, hereinafter referred to abbreviated as "USP", are used primarily in the railway track system to reduce dynamic impacts from train traffic, passed from vehicle wheels to rail tracks, elements of the fastening system and rail supports (sleepers or sleepwalkers) for ballast. The USP may cover the bottom surface of the sleeper /switch sleeper (Fig. 1a) entirely or occur only in the area under rails (Fig. 1b). In a railway track system with ballast structure, the USP should fulfill the following functions:

- limit the adverse impact of railway traffic on the environment by reducing the level of impacts in the form of material and acoustic vibrations (vibrations and noise); 
- reduce the stresses present in the ballast layer by increasing the contact area between the bottom of the foundation and ballast, thus increasing the service life of the railway track system structure.

There are many varieties of USP in the market that differ in thickness and stiffness, which allows their use in a wide range of loads and train speeds, with different solutions for the construction of railway surface and various requirements for fulfilling the above functions each individually or in combination. Each of these functions requires fulfillment of requirements concerning the strength and durability of the material from which USP are made and their connection with the foundation or switch sleeper. If the main function of using USP is to reduce environmental impacts, in addition to the strength criteria, the basic criteria for the selection of a particular type of USP should be included in the model analyzes such parameters as:

- permissible rail deflection value, which is not determined in the provisions of PKP PLK (technical standards) for specific operating conditions assigned to particular types of lines and track classes;

- natural frequency of objects that should be protected against the destructive effect of vibrations on the passage of trains, this frequency is a parameter related to many factors - mainly with the construction and ground and water conditions of the foundation of individual objects and can be determined on the basis of numerical tests or empirical.

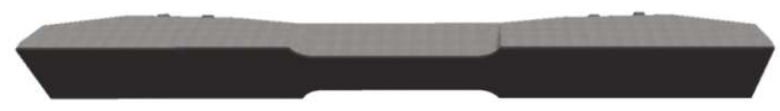

a)

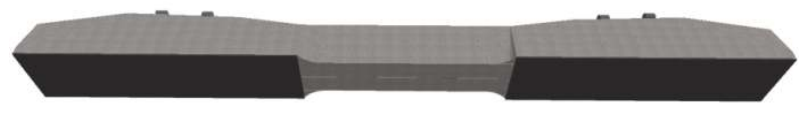

b)

1. USP: a) complete coverage of the lower surface of foundation; b) partial covering of the lower surface of the foundation

If the use of USP mainly aims at reducing the stresses occurring in the ballast layer, then the criteria for the selection of a suitable variant of the pads may be limited to testing and analysis of mechanical parameters determining the durability and strength of the material of these pads. USP are made of elastomeric materials (usually in the range of $5 \div 20 \mathrm{~mm}$ ) and are available in two material variants: based on polyurethane with closed or open pores and based on mixtures of natural rubber and synthetic rubber. The research presented in the paper has the character of preliminary identification of material characteristics of selected three varieties of USP and based on the results of these tests, selection of at least one of these variations for further comprehensive laboratory tests established in the project's program. The testing program is based on the PN-EN 16730 standard [8], including the quantitative limitation of load cycles justified by the preliminary, exploratory nature of tests, the quality of which includes test procedures for mandatory standard parameters assigned in the standard [8] for type approval tests (product homologation), and not procedures for testing the quality control of products that are also covered by this standard.

\section{Static and dynamic elastic properties of USP}

The basic parameters characterizing the elastic properties of USP, evaluated due to their main functions described above, are static and dynamic stiffness modules $[4,5,6]$. They affect the effectiveness of damping vibration transmission and noise emission to the environment of railway lines [12]. For USP with a higher value of stiffness modules, this efficiency will be lower than for pads with lower stiffness values. However, one must bear in mind that the use of a USP with a very low static stiffness modulus, results in a greater vertical deflection of the 
rail causing fatigue phenomena in the rail and in other components of the railway track structure. The values of the static and dynamic stiffness module of the USP pad can be in a wide range of values. In the case of a static stiffness modulus, it usually ranges from $\sim 0.02 \mathrm{~N}$ $/ \mathrm{mm}^{3}$ to $\sim 0.35 \mathrm{~N} / \mathrm{mm}^{3}$ and depends on the type and structure of the material, the thickness of the pad, the value of the load-interval in which the stiffness module and the frequency of loads are determined in the case of the dynamic module.

Static stiffness modules of the USP $\mathrm{C}_{\text {stat }}, \mathrm{Ct}_{\text {end }}\left[\mathrm{N} / \mathrm{mm}^{3}\right]$ pads are the ratio of static pressure/stress of a specified value [N/ $\mathrm{mm} 2]$, applied to a sample with a defined crosssectional area, to the sample deflection $[\mathrm{mm}]$ which this pressure causes. It characterizes the deflection of the rail course under the pressure of a non-moving rolling stock and affects the vertical deflection of the track grid. The value of the static stiffness module of the USP depends on the pressure, but it is not a linear relationship. Therefore, it is determined for various load ranges depending on the intended use of the pad: tram, metro, city rail or heavy rail. These ranges depending on operational parameters (maximum velocity and axial thrusts) are defined in PN-EN 16730 [8] for four-track categories: TC1, TC2, TC3 and TC4 (TC Track Category) defined in this normal.

The dynamic stiffness module of the USP is the ratio of the dynamic pressure of a certain value and frequency applied to the sample with a defined cross-sectional area, to the deflection of the specimen which this pressure causes. Thus, it characterizes the work of the USP under the pressure of moving rolling stock. The value of the dynamic stiffness module of the pad depends not only on the pressure, as in the static stiffness module of the pad, but also on the frequency of cyclic loads, therefore it should be determined under normalized pressure and frequency specified in the PN-EN 16730 standard [8].

\section{Durability of USP}

The durability of USP is assessed by examining their mechanical fatigue strength and the influence of long-term dynamic loads on the variability of determined parameters in relation to the value identified at the beginning of the tests. This test consists of a three-stage dynamic load of a USP specimen stuck to a concrete block, simulating operating loads in laboratory conditions. The dynamic loads exerted by the pulsator are sinusoidal with a frequency of up to $15 \mathrm{~Hz}$ and exerted with a harmonic force of values between $12 \mathrm{kN}$ and $32 \mathrm{kN}$ depending on:

- the static value range of the stiffness modulus of the tested pad - the force values are taken incrementally depending on the static value of the stiffness modulus of the tested pad;

- TC track category - values of forces adopted incrementally depending on axle load and speed assigned to particular track categories in the standard [8];

- I, II or III load level (I - 2000 cycles, II - 2000 cycles, III - up to a total of 3 million cycles).

Positive evaluation of the operational suitability of the tested USP includes the statement of the lack of visually determined mechanical damages, such as crushing, cracking, etc., as well as the determination of the static and dynamic change range (for $5 \mathrm{~Hz}$ ) of the stiffness module of the washer caused by the long-term dynamic load. Bearing in mind the surface of ballast construction, replacing the USP with insufficient durability would involve repairing the main surface (replacement of the track grid). That is why this property is important for infrastructure managers who cannot afford the durability of the USP pad to deviate from the durability of the foundation or switch sleeper.

This paper presents the results of fatigue strength tests for three different (material) USP pads:

- 002 - pad based on $9 \mathrm{~mm}$ thick SBR rubber granulate (v. 1);

- 004 - pad based on 9 mm thick SBR rubber granulate (v. 2); 
- 007 - pad based on polyurethane, $7 \mathrm{~mm}$ thick.

Pads No. 002 and 004 are made in two versions based on the same raw material, but they differ in production technology and density.

The tested samples were $250 \mathrm{~mm}$ x $250 \mathrm{~mm}$ x USP thick and were glued to 250 mmx250 mm x $100 \mathrm{~mm}$ concrete blocks. Tests (Fig. 2) were carried out at room temperature using a specially profiled geometric figures, a GBP steel plate (Geometric Ballast Plate) [6, 8]. Three parameters for the TC3 category were determined for each sample: $\mathrm{C}_{\text {stat }}-$ static stiffness module for the load range prevailing in operation $(0.01 \div 0.1) \mathrm{N} / \mathrm{mm}^{2}, \mathrm{C}_{\text {tend }}$ - static stiffness modulus for the load range $(0.01 \div 0,2) \mathrm{N} / \mathrm{mm}^{2}$ and Cdyn05 - dynamic stiffness module for the $5 \mathrm{~Hz}$ load frequency, determined by the force method (pulsator controlled by the value of the present interval of acting sample load forces). The tests were carried out up to 500,000 cycles (less than the standard 3 million cycles), which is justified by the preliminary nature of the study and sufficient to select USP for further analysis and rejecting those that do not promise that they will meet the requirements as a vibroinsulation element with permanent properties.

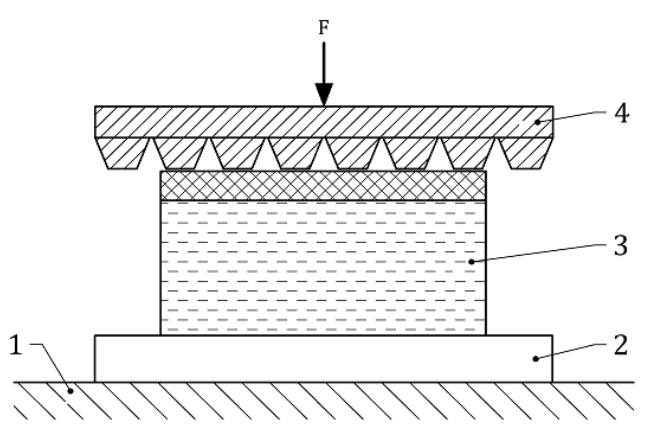

a)

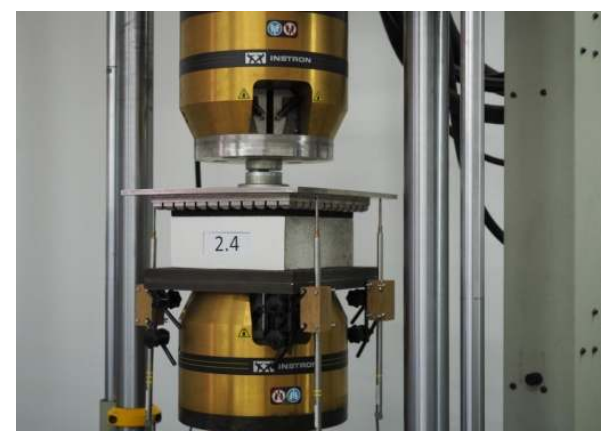

b)

2. Fatigue testing of USP shims: a) test scheme (1 - rigid and non-deformable substrate/support, 2 - steel plate, 3 - USP fixed to the concrete block, 4 - profiled pressure plate/load plate GBP); b) material sample No. 002 on the test bench

Static and dynamic values of stiffness modules and their changes before and after the fatigue strength test for three samples are presented in Tables 1-3. The table contains the initial values (before the fatigue test "material number"), values after 100, 200, 300, 400 and 500 thousand. load cycles "material number_100 / 200/300/400/500" and values determined after one to two weeks after ending the fatigue tests "material number_500_post".In Figures 3-5, the graphs of the characteristics obtained in the static and dynamic tests of USP washers are presented.

Tab. 1. Values of static and dynamic stiffness modules for material sample No. 002 and their changes after successive series of loads - fatigue strength test.

\begin{tabular}{|c|c|c|c|c|c|c|c|c|}
\hline \multirow[b]{2}{*}{ Parameter } & \multicolumn{8}{|c|}{ Modulus of rigidity $\left[\mathrm{N} / \mathrm{mm}^{3}\right]$ : } \\
\hline & $\begin{array}{c}002 \\
\text { _0 }\end{array}$ & $\begin{array}{c}002 \\
-100\end{array}$ & $\begin{array}{c}002 \\
200\end{array}$ & $\begin{array}{c}002 \\
-300\end{array}$ & $\begin{array}{c}002 \\
-400\end{array}$ & $\begin{array}{c}002 \\
\mathbf{5 0 0}\end{array}$ & $\begin{array}{c}002 \_ \\
500 \text { _post }\end{array}$ & $\begin{array}{c}\Sigma \Delta \\
{[\%]}\end{array}$ \\
\hline $\begin{array}{c}\mathrm{C}_{\text {stat }} \\
(0.01-0.10)\end{array}$ & 0,051 & 0,059 & 0,059 & 0,061 & 0,061 & 0,059 & 0,053 & 3,9 \\
\hline $\begin{array}{c}\mathrm{C}_{\text {tend }} \\
(0.01-0.20)\end{array}$ & 0,073 & 0,082 & 0,082 & 0,084 & 0,084 & 0,082 & 0,075 & 2,7 \\
\hline $\mathrm{C}_{\mathrm{din} 05}$ & 0,069 & 0,076 & 0,076 & 0,078 & 0,079 & 0,077 & 0,071 & 2,9 \\
\hline
\end{tabular}




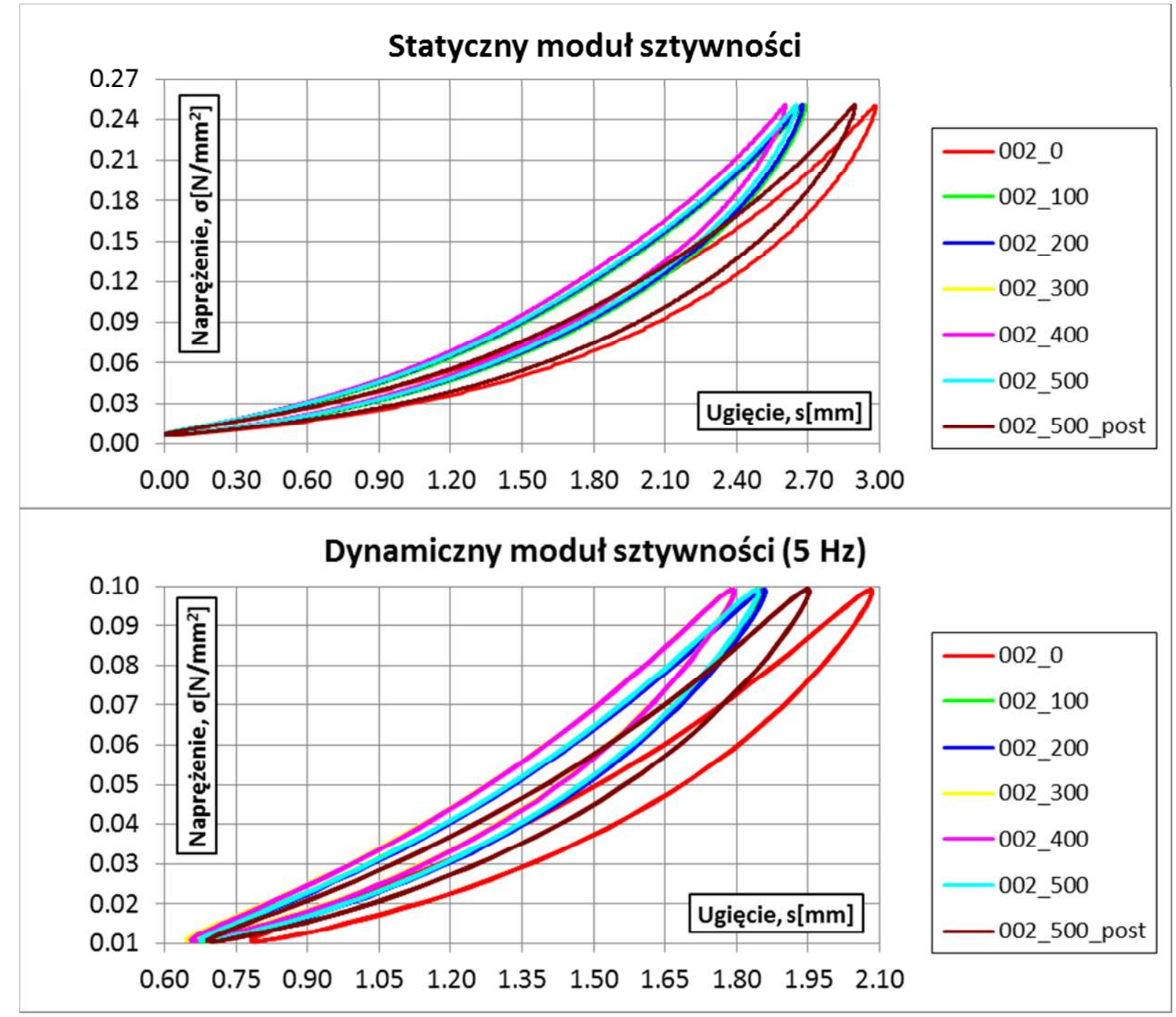

3. Static and dynamic stiffness modules for material sample No 002 - Fatigue strength test.

Tab. 2. Values of static and dynamic stiffness modules for material sample 004 and their changes after successive load series - fatigue strength test.

\begin{tabular}{|c|c|c|c|c|c|c|c|c|}
\hline \multirow{2}{*}{ Parameter } & \multicolumn{7}{|c|}{ Modulus of rigidity [N/mm $\mathbf{3}]:$} \\
\cline { 2 - 9 } & $\mathbf{0 0 4}$ & $\mathbf{0 0 4}$ & $\mathbf{0 0 4}$ & $\mathbf{0 0 4}$ & $\mathbf{0 0 4}$ & $\mathbf{0 0 4}$ & $\mathbf{0 0 4}$ & $\mathbf{\Sigma} \boldsymbol{\mathbf { 0 }}$ \\
\hline $\begin{array}{c}\mathrm{C}_{\text {stat }} \\
(0.01-0.10)\end{array}$ & 0,054 & 0,070 & 0,070 & 0,073 & 0,077 & 0,077 & 0,076 & 40,7 \\
\hline $\begin{array}{c}\mathrm{C}_{\text {tend }} \\
(0.01-0.20)\end{array}$ & 0,080 & 0,100 & 0,100 & 0,103 & 0,107 & 0,107 & 0,107 & 33,8 \\
\hline $\mathrm{C}_{\text {din } 05}$ & 0,075 & 0,088 & 0,088 & 0,092 & 0,096 & 0,098 & 0,103 & 37,3 \\
\hline
\end{tabular}




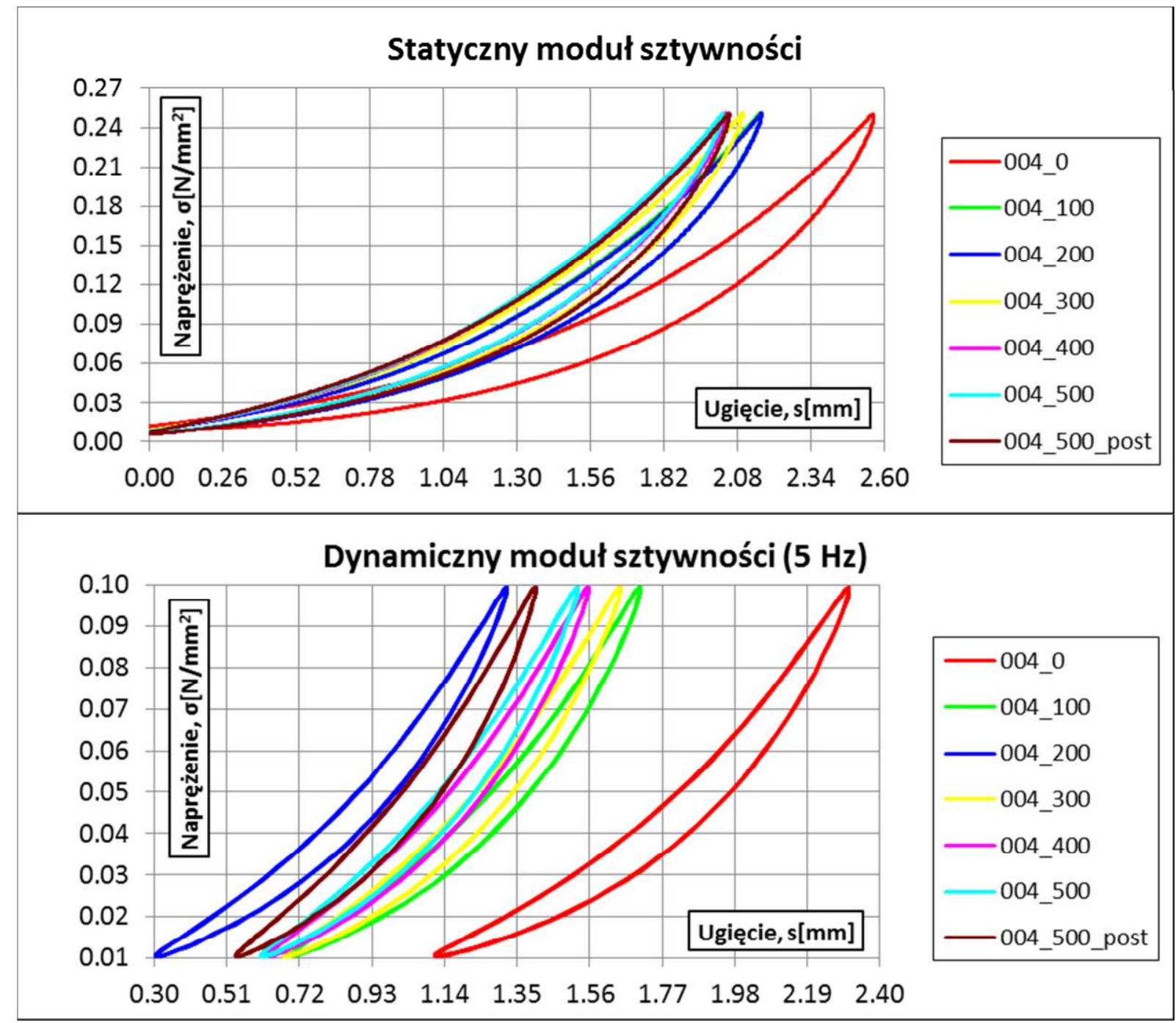

4. Static and dynamic stiffness modules for material sample No 004 - Fatigue strength test.

Tab. 3. Values of static and dynamic stiffness modules for material sample 007 and their changes after successive load series - fatigue strength test.

\begin{tabular}{|c|c|c|c|c|c|c|c|c|}
\hline \multirow[b]{2}{*}{ Parameter } & \multicolumn{8}{|c|}{ Modulus of rigidity [N/mm $\left.{ }^{3}\right]$ : } \\
\hline & $\begin{array}{r}007 \\
-0\end{array}$ & $\begin{array}{c}007 \\
-100\end{array}$ & $\begin{array}{c}007 \\
200\end{array}$ & $\begin{array}{c}007 \\
300 \\
\end{array}$ & $\begin{array}{c}007 \\
-400\end{array}$ & $\begin{array}{c}007 \\
-500 \\
\end{array}$ & $\begin{array}{c}007_{-} \\
500 \text { _post }\end{array}$ & $\begin{array}{c}\Sigma \Delta \\
{[\%]}\end{array}$ \\
\hline $\begin{array}{c}\mathrm{C}_{\text {stat }} \\
(0.01-0.10)\end{array}$ & 0,087 & 0,103 & 0,108 & 0,108 & 0,111 & 0,113 & 0,088 & 1,1 \\
\hline $\begin{array}{c}\mathrm{C}_{\text {tend }} \\
(0.01-0.20)\end{array}$ & 0,117 & 0,133 & 0,139 & 0,138 & 0,142 & 0,144 & 0,120 & 2,6 \\
\hline $\mathrm{C}_{\mathrm{din} 05}$ & 0,111 & 0,130 & 0,139 & 0,139 & 0,143 & 0,145 & 0,117 & 5,4 \\
\hline
\end{tabular}




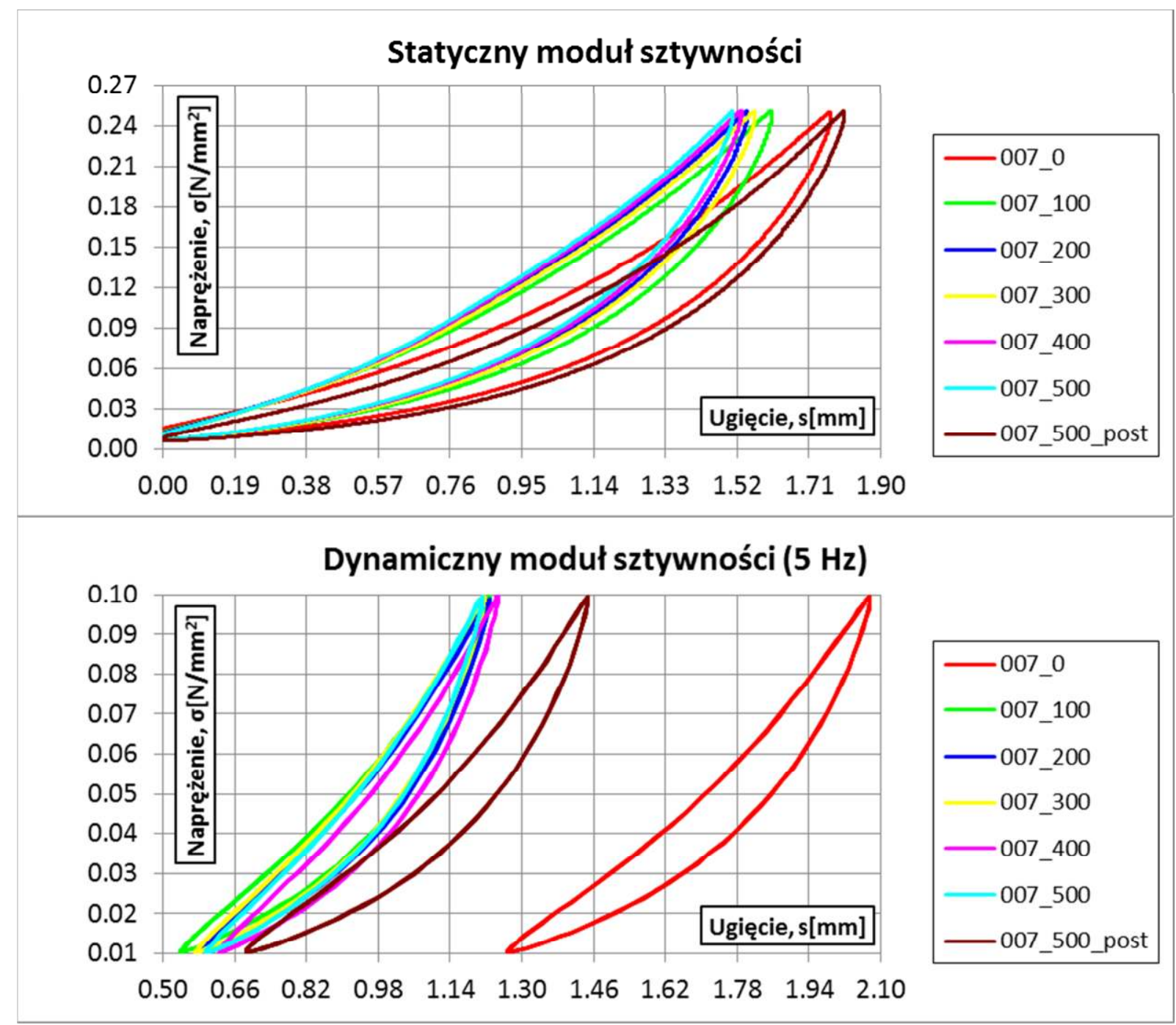

5. Static and dynamic stiffness modules for material sample No 007 - Fatigue strength test.

Analysis of these results shows that the most favorable properties from the point of view of fatigue life are shown in material No. 002. Stiffness changes are small, and stiffness curves after a period of one to two weeks after the end of fatigue tests are close to the initial curves. The worst properties have a material sample No. 004, for which the stiffness changes exceed $30 \%$, which significantly exceeds the admissible values for elastic products used in the railway surface accepted in the literature (the limit value is usually taken as $15-25 \%[2,9$, 10]).

\section{Resistance to weather conditions}

Due to the occurrence of rainwater in the ballast and the difference in temperature occurring in our climate zone, testing USP in terms of their resistance to water, frost resistance, and high temperatures are justified. The temperature lasting for at least two weeks in winter is below $15^{\circ} \mathrm{C}$ and its oscillation around $0^{\circ} \mathrm{C}$ is not uncommon in our country.

In the weather resistance test, a USP sample glued to a concrete cube is stored in water for $24 \mathrm{~h}$ (Figure 6), and then cyclically frozen to $-15^{\circ} \mathrm{C}$ in $4 \mathrm{~h}$, left at this temperature for $8 \mathrm{~h}$, after which the temperature is increased to $+40^{\circ} \mathrm{C}$ in 4 hours (at $80 \%$ relative humidity) and the sample remains in it for 8 hours (Fig. 7). One cycle lasts $24 \mathrm{~h}$ and 7 full freeze-thaw cycles must be carried out. 


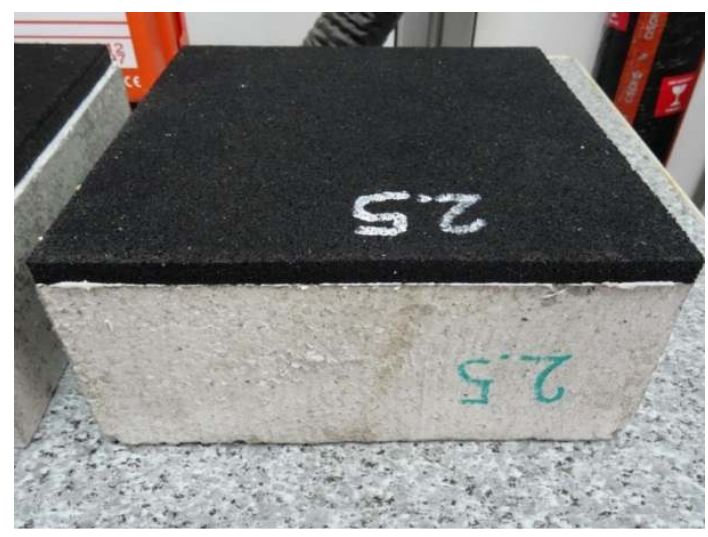

a)

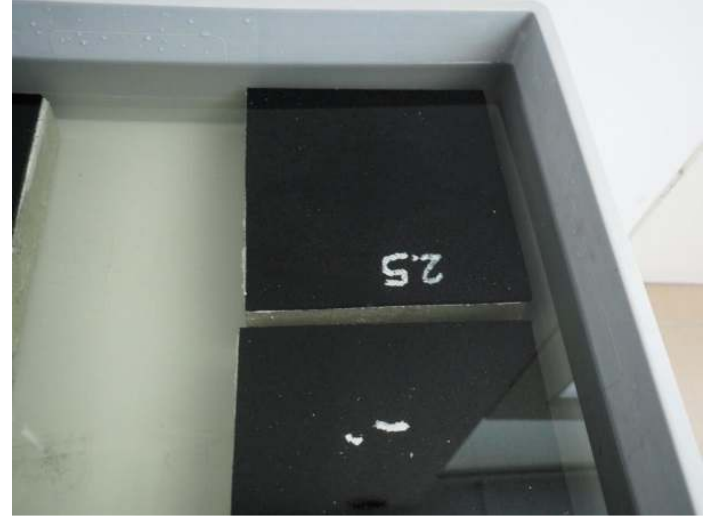

b)

6. Material sample No. 002: a) USP on a concrete block; b) a sample immersed in water for 24 hours

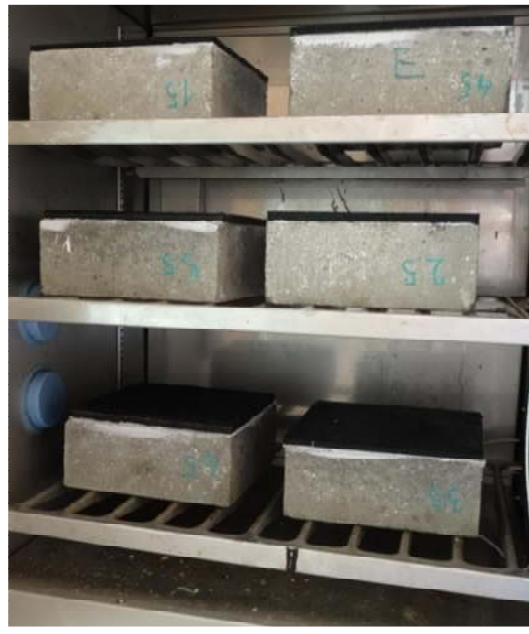

a)

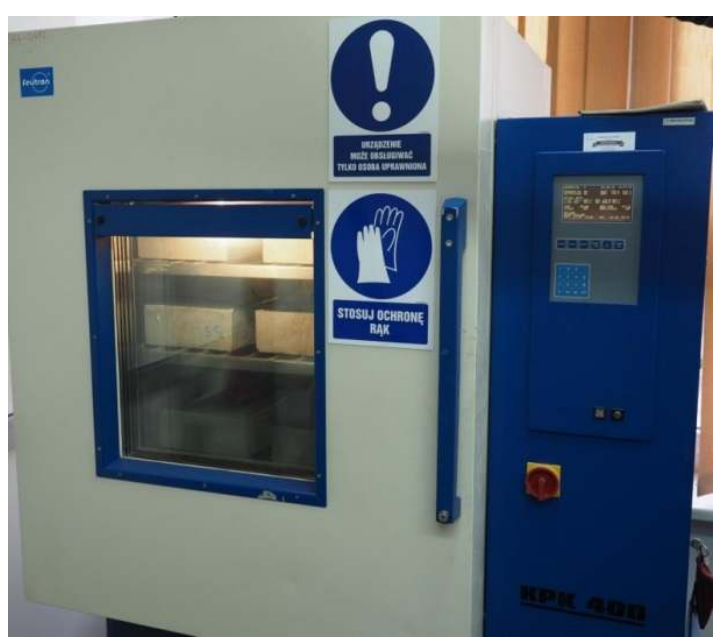

b)

7. Samples of USP during tests of resistance to weather conditions: a) samples in a climatic chamber; b) climatic chamber with tested samples.

In the case of weather resistance tests, a change (determined within $1 \div 2$ weeks from the end of the test) is important: static and dynamic (for $5 \mathrm{~Hz}$ ) stiffness module of the USP, no damage to the pad and a high value of adhesion to the concrete by pull off.

The results of static and dynamic stiffness modulus tests are presented in tables 4-6 and in diagrams (Figs. 8-10), taking into account initial values (before weather resistance test "material_pre-number") and final (after 1 - 2 weeks from removal from the climate chamber "material number_post"). The best resistance to weather conditions is shown in material No. 004, worst in No. 007.

Tab. 4. Values of static and dynamic stiffness modules for material sample 002 and their changes - weather resistance test.

\begin{tabular}{|c|c|c|c|}
\hline \multirow{2}{*}{ Parameter } & \multicolumn{3}{|c|}{ Modulus of rigidity [N/mm3]: } \\
\cline { 2 - 4 } & 002_pre & 002_post & $\mathbf{\Sigma} \boldsymbol{\Delta}[\%]$ \\
\hline $\mathrm{C}_{\text {stat }}(0.01-0.10 \mathrm{~N} / \mathrm{mm} 2)$ & 0,051 & 0,054 & 5,9 \\
\hline $\mathrm{C}_{\text {tend }}(0,01-0,20 \mathrm{~N} / \mathrm{mm} 2)$ & 0,071 & 0,076 & 7,0 \\
\hline $\mathrm{C}_{\mathrm{din} 05}$ & 0,068 & 0,072 & 5,9 \\
\hline
\end{tabular}




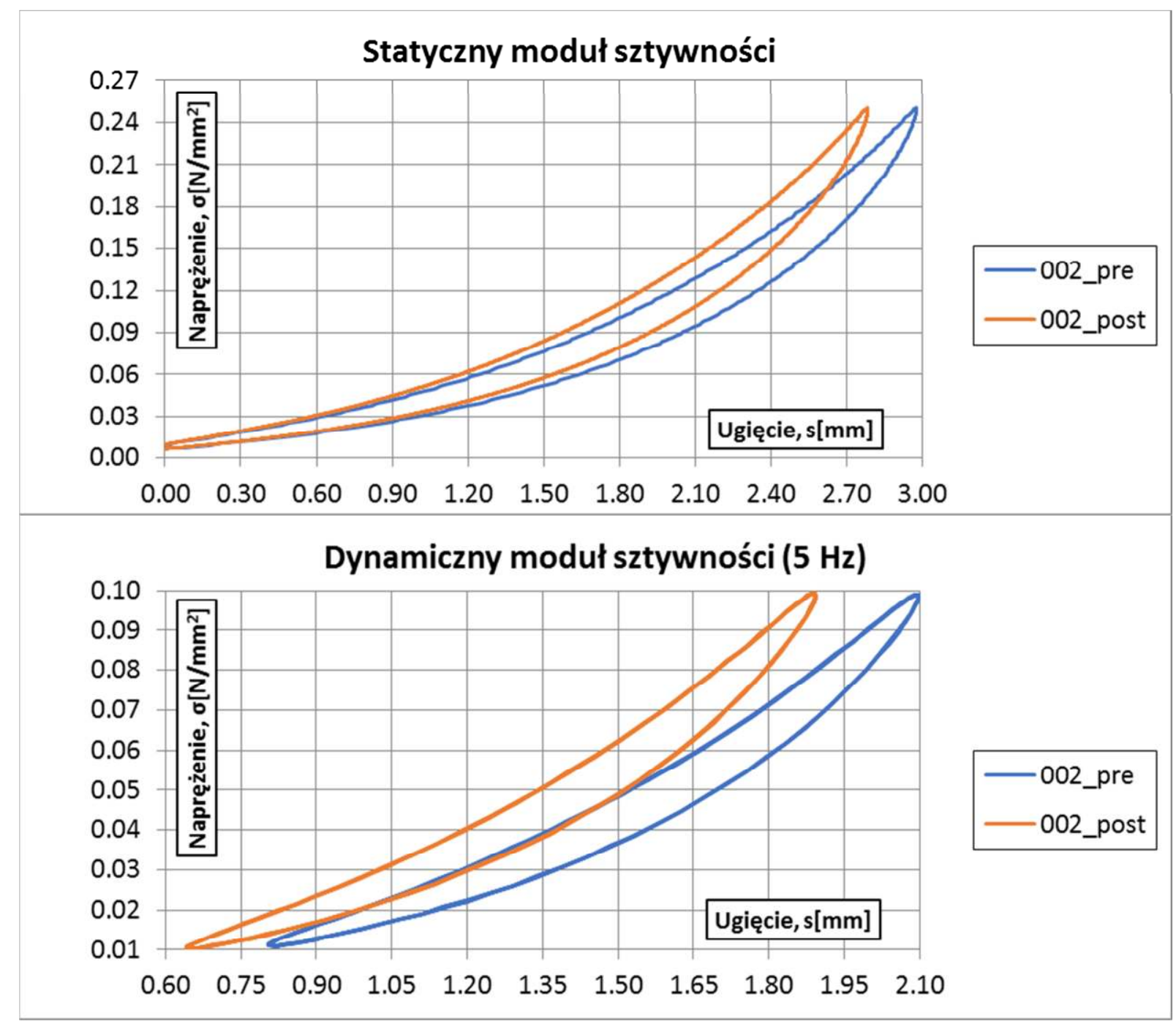

8. Static and dynamic stiffness modules for material sample No 002 - Weather resistance test

Tab. 5. Values of static and dynamic stiffness modules for material sample 004 and their changes - weather resistance test.

\begin{tabular}{|c|c|c|c|}
\hline \multirow{2}{*}{ Parameter } & \multicolumn{3}{|c|}{ Modulus of rigidity $\left[\mathrm{N} / \mathrm{mm}^{3}\right]$ : } \\
\hline & 002_pre & 002_post & $\Sigma \Delta[\%]$ \\
\hline $\mathrm{C}_{\text {stat }}(0.01-0.10 \mathrm{~N} / \mathrm{mm} 2)$ & 0,058 & 0,059 & 1,7 \\
\hline $\mathrm{C}_{\text {tend }}(0,01-0,20 \mathrm{~N} / \mathrm{mm} 2)$ & 0,086 & 0,088 & 2,3 \\
\hline $\mathrm{C}_{\mathrm{din} 05}$ & 0,079 & 0,083 & 5,1 \\
\hline
\end{tabular}




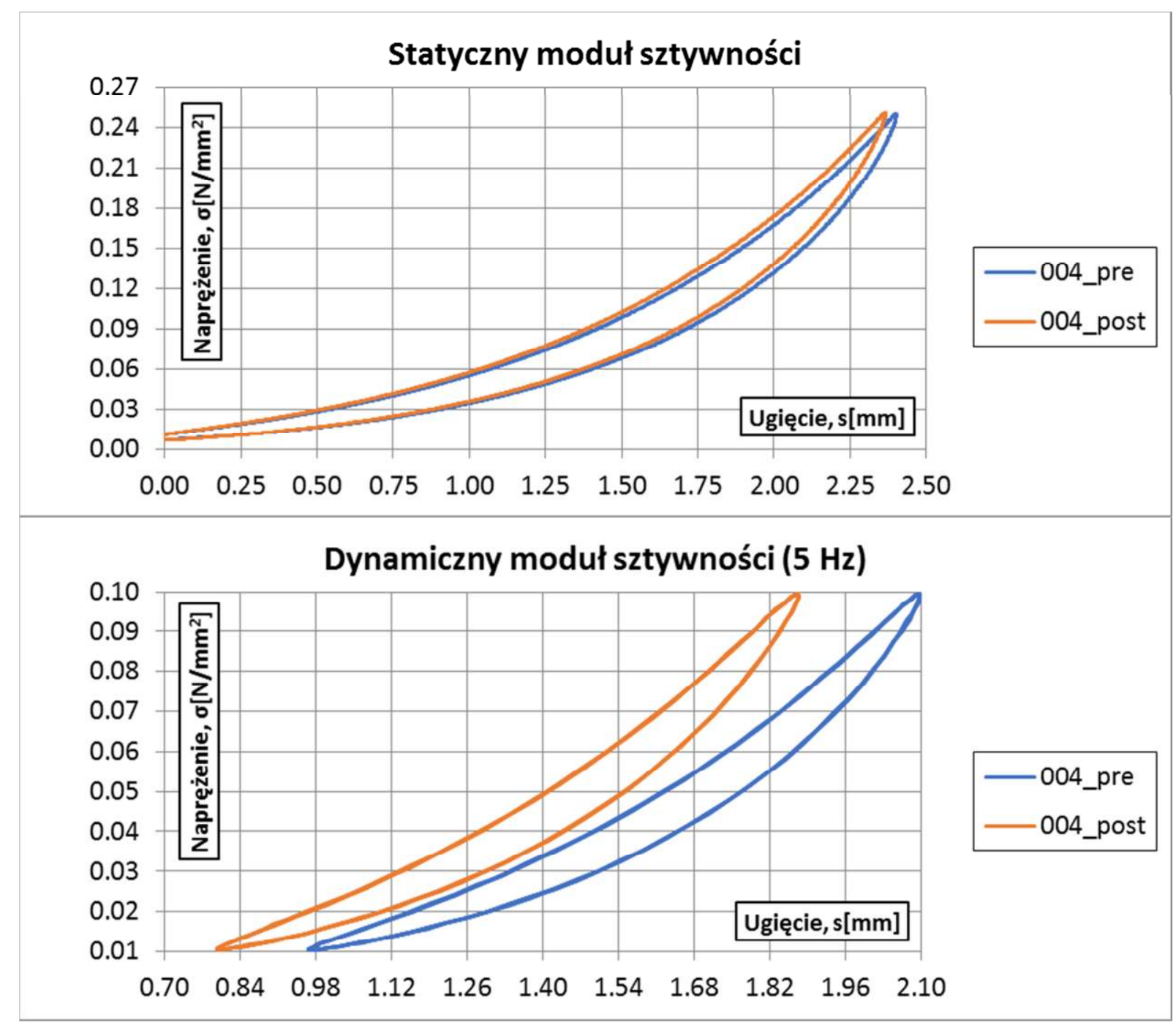

9. Static and dynamic stiffness modules for material sample No 004 - Weather resistance test

Tab. 6. Values of static and dynamic stiffness modules for material sample 007 and their changes - weather resistance test.

\begin{tabular}{|c|c|c|c|}
\hline \multirow{2}{*}{ Parameter } & \multicolumn{3}{|c|}{ Modulus of rigidity $\left[\mathrm{N} / \mathrm{mm}^{3}\right]$ : } \\
\hline & 002_pre & 002_post & $\Sigma \Delta[\%]$ \\
\hline $\mathrm{C}_{\text {stat }}(0.01-0.10 \mathrm{~N} / \mathrm{mm} 2)$ & 0,080 & 0,116 & 45,0 \\
\hline $\mathrm{C}_{\text {tend }}(0,01-0,20 \mathrm{~N} / \mathrm{mm} 2)$ & 0,105 & 0,149 & 41,9 \\
\hline $\mathrm{C}_{\mathrm{din} 05}$ & 0,106 & 0,164 & 54,7 \\
\hline
\end{tabular}




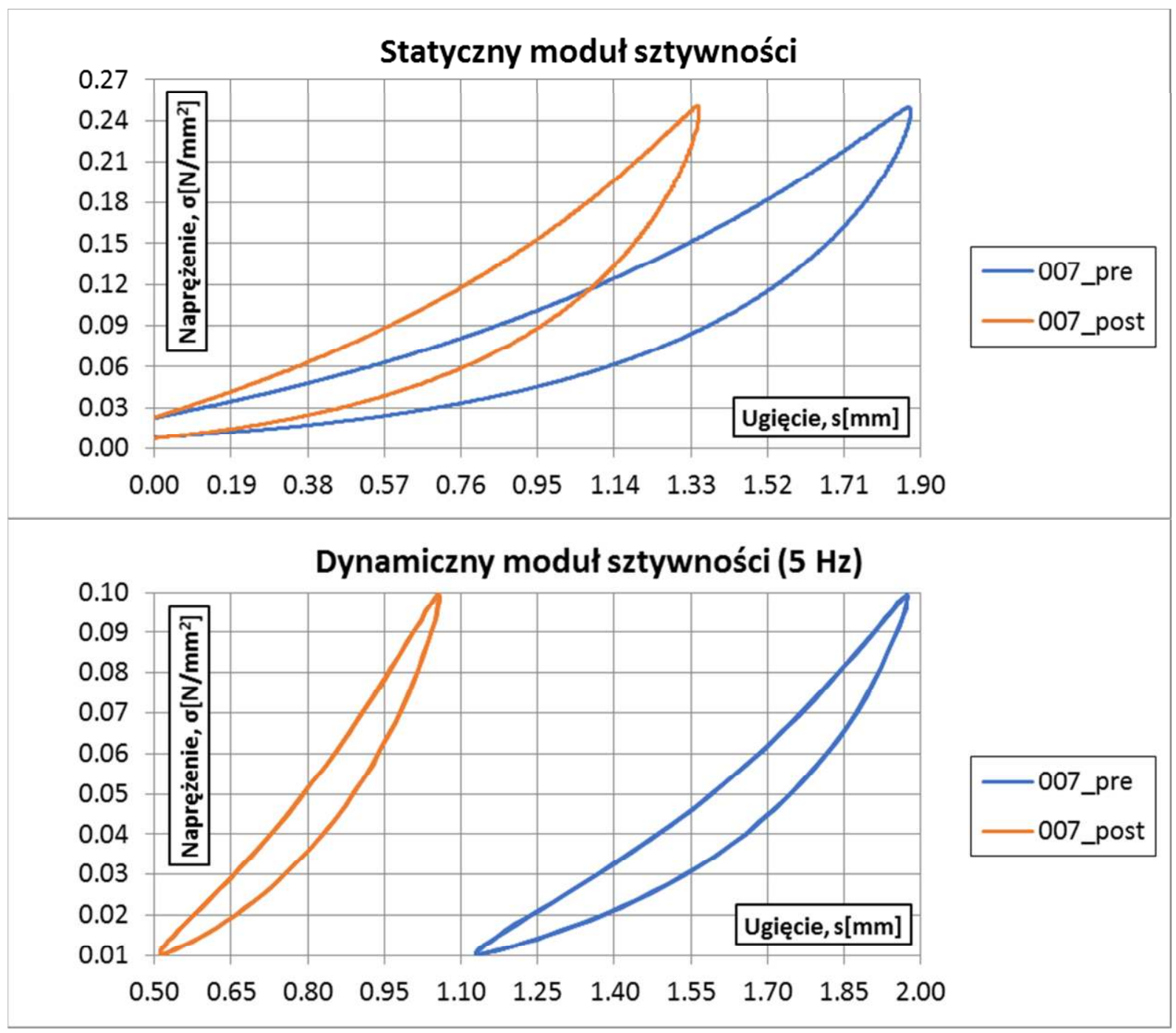

10. Static and dynamic stiffness modules for material sample No 007 - Weather resistance test

Comparing the results of both studies, it can be concluded that: Material No. 002 has good properties in terms of fatigue strength and resistance to weather conditions; material No. 004, despite very good resistance to weather conditions, should be rejected due to unacceptable fatigue test result; material No. 007 has quite a good durability (fatigue strength), however, it is not resistant to weather conditions.

\section{Conclusions}

1) The laboratory tests carried out showed the desirability of using a limited quantitative scope for the material preselection of USP pads intended for further testing to the full extent set in the PN-EN 16730 standard [8].

2) Three parameters were determined for each of the materials: static stiffness modulus for the load range $(0.01 \div 0.1) \mathrm{N} / \mathrm{mm}^{2}$, static stiffness modulus for the load range $(0.01$ $\div 0.2) \mathrm{N} / \mathrm{mm}^{2}$ and dynamic module stiffness for $5 \mathrm{~Hz}$ (determined by force method) with a limitation of 500 thousand load cycles in the fatigue strength test.

3) In atmospheric resistance tests, previously stored in water samples of pads (USP) were subjected to 7 alternate freeze-thaw cycles (temperature change from $-15^{\circ} \mathrm{C}$ to $+40^{\circ}$ C). 
4) The results of the tests, combined with the model analyzes and the analysis of the state of knowledge, have shown that for a reliable assessment of the suitability of UPS pads to meet the functions set for them, both fatigue tests and weather resistance tests are necessary. The tested parameters show different relations between the material of USP shims and physical features that affect their damping properties, which in turn affects their effectiveness of vibroisolation throughout their lifetime.

5) Of the three materials tested (USP) pads, only one material showed the expected properties in both tests. The other two materials will not be subject to further testing, because they do not have sufficient durability or are not weather-resistant and should not be used as vibroacoustic insulators.

The publication was created as part of the project "Innovative solutions for the protection of people and buildings against vibrations from rail traffic". The project is co-financed by the European Union from the European Regional Development Fund under the Intelligent Development Operational Program and by PKP PLK S.A. within the framework of the BRIK joint venture.

Fundusze Europejskie

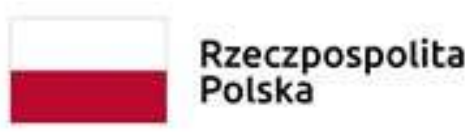

\author{
Unia Europejska \\ Europejskie Fundusze \\ Strukturalne i Inwestycyine
}

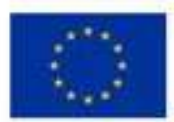

\section{Source materials}

[1] Abadi T., Le Pen L., Zervos A., Powrie W. Effect of Sleeper Interventions on Railway Track Performance. Journal of Geotechnical and Geoenvironmental Engineering, 2019, 145, 4, 04019009.

[2] IRS 70713-1: Railway Application - Track \& Structure "Under Sleeper Pads (USP) Recommendations for Use", 1 st edition 01.04.2018.

[3] Jayasuriya C., Indraratna B., Ngo T.N. Experimental study to examine the role of under sleeper pads for improved performance of ballast under cyclic loading. Transportation Geotechnics, 2019, 19, 61-73.

[4] Kraśkiewicz C., Lipko C., Płudowska M., Oleksiewicz W., Zbiciak A.: Static and Dynamic Characteristics of Resilient Mats for Vibration Isolation of Railway Tracks. Procedia Engineering, 2016, 153, 317-324.

[5] Kraśkiewicz C., Oleksiewicz W., Płudowska-Zagrajek M., Piotrowski A. Testing procedures of the Under Sleeper Pads applied in the ballasted rail track systems. MATEC Web of Conferences, 2018, 196, 02046.

[6] Kraśkiewicz C., Oleksiewicz W., Zbiciak A.: Underlay pads in the subgrade construction of railroad pavement - technical and formal aspects of application. Institute of Civil Engineering Archives, 2017, 25, 221-243.

[7] Omodaka A., Kumakura T., Konishi T. Maintenance reduction by the development of resilient sleepers for ballasted track with optimal under-sleeper pads. Procedia CIRP, 2017, 59, 53-56.

[8] PN-EN 16730:2016-08 Railway Engineering - Track - Concrete sleepers and turnout sleepers with sleeper sleepers, Polish Committee for Standardization, 2016.

[9] RFI TCAR SF AR 03007 C, Technical delivery specification: USP mats, 2017.

[10] SNCF IG04013 Crossbeams and concrete supports for ballasted paving equipped with resilient underside footings (ex CT IGEV 016) 14.08.2018. 
[11] Sol-Sánchez M., Moreno-Navarro F., Rubio-Gámez C. The use of elastic elements in railway tracks: A state of the art review. Construction and Building Materials, 2015, 75, 293-305.

[12] Zbiciak A., Kraśkiewicz C., Oleksiewicz W., Płudowska-Zagrajek M., Lipko C. Mechanical modelling and application of vibroacoustic isolators in railway tracks. MATEC Web of Conferences, 2017, 117, 00090. 